\title{
Cholesterol biosynthesis inhibitor RO 48-807I suppresses growth of hormone-dependent and castration-resistant prostate cancer cells
}

This article was published in the following Dove Press journal:

OncoTargets and Therapy

30 May 2016

Number of times this article has been viewed

\author{
Yayun Liang' \\ Benford Mafuvadze' \\ Johannes D Aebi \\ Salman M Hyder' \\ 'Dalton Cardiovascular Research \\ Center and Department of \\ Biomedical Sciences, University \\ of Missouri-Columbia, Columbia, \\ MO, USA; ${ }^{2}$ Medicinal Chemistry, \\ Roche Pharma Research and \\ Early Development (pRED), \\ Roche Innovation Center Basel, \\ F Hoffmann-La Roche Ltd., Basel, \\ Switzerland
}

\begin{abstract}
Standard treatment for primary prostate cancer includes systemic exposure to chemotherapeutic drugs that target androgen receptor or antihormone therapy (chemical castration); however, drug-resistant cancer cells generally emerge during treatment, limiting the continued use of systemic chemotherapy. Patients are then treated with more toxic standard therapies. Therefore, there is an urgent need for novel and more effective treatments for prostate cancer. The cholesterol biosynthetic pathway is an attractive therapeutic target for treating endocrine-dependent cancers because cholesterol is an essential structural and functional component of cell membranes as well as the metabolic precursor of endogenous steroid hormones. In this study, we have examined the effects of RO 48-8071 (4'-[6-(allylmethylamino)hexyloxy]-4-bromo-2'-fluorobenzophenone fumarate; Roche Pharmaceuticals internal reference: RO0488071) (RO), which is an inhibitor of 2,3-oxidosqualene cyclase (a key enzyme in the cholesterol biosynthetic pathway), on prostate cancer cells. Exposure of both hormone-dependent and castration-resistant human prostate cancer cells to RO reduced prostate cancer cell viability and induced apoptosis in vitro. RO treatment reduced androgen receptor protein expression in hormone-dependent prostate cancer cells and increased estrogen receptor $\beta(\mathrm{ER} \beta)$ protein expression in both hormonedependent and castration-resistant prostate cancer cell lines. Combining RO with an ER $\beta$ agonist increased its ability to reduce castration-resistant prostate cancer cell viability. In addition, RO effectively suppressed the growth of aggressive castration-resistant human prostate cancer cell xenografts in vivo without any signs of toxicity to experimental animals. Importantly, RO did not reduce the viability of normal prostate cells in vitro. Our study is the first to demonstrate that the cholesterol biosynthesis inhibitor RO effectively suppresses growth of human prostate cancer cells. Our findings suggest that cholesterol biosynthesis inhibitors such as RO, when used in combination with commonly used chemotherapeutic drugs or ER $\beta$ specific ligands, could represent a novel therapeutic approach to prevent the growth of prostate cancer tumors.
\end{abstract}

Keywords: prostate cancer, cholesterol biosynthesis inhibitor, cell viability, xenograft, castration resistant

\section{Introduction}

Despite concerted efforts to develop new strategies for preventing and treating prostate cancer, almost 240,000 new cases are reported each year in the US and more than 28,000 males die of the disease annually. ${ }^{1}$ In addition, prostate cancer is associated with significant physical burden, including bowel, urinary, and sexual dysfunction in early-stage disease and painful bony lesions in more advanced cancers. ${ }^{2,3}$ Most deaths from prostate cancer occur due to complications that arise following metastasis from the primary tumor to other tissues and organs, a process dependent
Correspondence: Salman M Hyder Dalton Cardiovascular Research Center, University of Missouri-Columbia, I34 Research Park Drive, Columbia, MO 6521I, USA

$\mathrm{Tel}+\mid 573882$ |26|

Fax +I 5738844232

Email hyders@missouri.edu 
upon increased angiogenesis. ${ }^{4}$ Human prostate cancer cells often proliferate in response to endogenous or exogenous androgens and estrogens, which also inhibit cell death and promote metastasis. ${ }^{5}$ Whereas chemical castration, in the form of systemic exposure to chemotherapeutic drugs or antihormones, is the standard treatment for primary prostate cancer, drug-resistant cancer cells often emerge, limiting the usefulness of continued chemotherapy. ${ }^{5}$ In addition, many patients suffering from prostate cancer fail to respond to any form of hormonal therapy, leading to poor clinical prognosis. As a consequence, novel, less toxic, and more effective treatments for prostate cancer are urgently needed.

Cholesterol is an essential structural and functional component of cell membranes and also the metabolic precursor of endogenous steroid hormones. In addition, cholesterol is associated with increased angiogenesis in prostate tumors., ${ }^{4,6}$ Consequently, the pathway leading to cholesterol biosynthesis is an attractive therapeutic target through which endocrinedependent cancers might be treated. Historically, statins have been used to inhibit 3-hydroxy-3-methyl-glutaryl-coenzyme A (HMG-CoA) reductase, an enzyme essential for cholesterol biosynthesis to treat cancer. ${ }^{7}$ However, statins cause a number of undesirable side effects attributed to reduced levels of isoprenoids, defective posttranslational modification of membrane proteins, and impaired membrane structure and function. ${ }^{8}$ Alternative approaches using different cholesterol biosynthesis inhibitors are currently being considered to lower cholesterol levels. 2,3-oxidosqualene cyclase (OSC), an enzyme that acts downstream of HMG-CoA reductase to convert 2, 3-monoepoxysqualene to lanosterol (a key step in the biosynthesis of cholesterol) has emerged as a possible new target by which to inhibit cholesterol biosynthesis. ${ }^{9}$ RO 48-8071 (4'-[6-(allylmethylamino)hexyloxy]-4-bromo$2^{\prime}$-fluorobenzophenone fumarate; Roche Pharmaceuticals internal reference: RO0488071) (RO) is a potent inhibitor of OSC..$^{10,11}$ For this reason, we conducted a series of studies to examine the anticancer properties of RO. In the studies reported here, we found that $\mathrm{RO}$ exerts a number of novel effects that might be exploited to treat or prevent prostate cancer. RO reduced viability of both hormone-dependent and castration-resistant prostate cancer cells, but not normal prostate cells, in vitro; in addition, RO induced apoptosis of both hormone-dependent and castration-resistant prostate cancer cells in vitro. RO also simultaneously lowered levels of androgen receptor (AR), a pro-proliferative protein, in hormone-dependent prostate cancer cells and induced estrogen receptor $\beta$ (ER $\beta)$, a potent antiproliferative protein, ${ }^{12-16}$ in both hormone-dependent and castrationresistant prostate cancer cells in vitro.
Finally, RO arrested the growth of human castration-resistant prostate cancer cell xenografts in vivo. These biological effects of RO suggest that it may represent a suitable therapeutic agent by which to arrest human prostate cancer cell growth in vivo.

\section{Materials and methods Cell lines and culture}

The AR $\alpha$-positive prostate cancer cell lines LNCaP and the castration-resistant cell lines PC-3 and DU145 were obtained from the American Type Culture Collection (ATCC, Manassas, VA, USA). A castration-resistant derivative cell line C4-2, derived from LnCaP cells, was obtained from UROCOR (Urosciences Group, Oklahoma City, OK, USA). Cells were grown in Dulbecco's Modified Eagle's Medium or Roswell Park Memorial Institute 1640 medium (RPMI-1640 medium) (Thermo Fisher Scientific, Waltham, MA, USA) supplemented with 10\%-20\% fetal bovine serum (Sigma-Aldrich Co., St Louis, MO, USA) as indicated. RWPE-1, a normal prostate cell line, was also obtained from ATCC and grown in complete growth medium according to instructions provided by the vendor. The University of Missouri Ethics Committee/Institutional Review Board does not require that ethical approval be obtained for the use of commercially available cell lines.

\section{Reagents}

RO was purchased from Sigma-Aldrich for in vitro experiments and obtained from Roche Pharmaceuticals (Basel, Switzerland, provided by Dr Johannes Aebi) for in vivo studies. ER $\beta$ (H-150, Cat\# sc-8974) and AR (N-20, Cat\# sc-816) antibodies were obtained from Santa Cruz Biotechnology, Inc. (Dallas, TX, USA). $\beta$-Actin antibody was obtained from Sigma-Aldrich. The ER $\beta$ agonist diarylpropionitrile $(\mathrm{DPN})^{17}$ was obtained from Tocris Biosciences (Ellisville, MO, USA).

\section{Cell viability assay}

The sulforhodamine B assay was used to measure cell viability, as previously described. ${ }^{18}$

\section{Cell apoptosis assay}

The Annexin V-fluorescein isothiocyanate (FITC) Apoptosis Detection Kit (Biovision Research Products, Mountain View, CA, USA) was used to measure apoptosis and cell death in prostate cancer cells, as we have previously described. ${ }^{19}$

\section{In vivo prostate cancer tumor growth inhibition assays}

All animal experiments were approved by the University of Missouri Animal Care Institutional Review Committee. 
This study adhered to the guidelines of the US Government Principles for the Utilization and Care of Vertebrate Animals Used in Testing, Research, and Training. Six-week-old male athymic nude mice (nu/nu, Foxn1) weighing 20-22 g were purchased from Harlan Sprague Dawley, Inc. (Indianapolis, IN, USA). Castration-resistant PC- 3 cells $\left(5 \times 10^{6}\right.$ in $0.15 \mathrm{~mL}$ solution) were mixed with matrigel and RPMI-1640 medium $(1 / 1, v / v)$ and injected subcutaneously into both flanks of each mouse ( $n=6$ animals/group) and tumors allowed to develop. The tumors were measured twice per week with a digital caliper as described previously. ${ }^{20}$ Tumor volumes were calculated by the formula $(\mathrm{L} \times \mathrm{W} \times \mathrm{H}) \times \pi / 6$. Drug treatment was started when tumor volumes reached $\sim 100 \mathrm{~mm}^{3}$. Mice were given daily tail vein injections of $0.1 \mathrm{~mL}$ solution of either 5 or $20 \mathrm{mg} / \mathrm{kg}$ RO for 5 days. This was followed by an injection every other day for six additional treatments and then a final injection 2 hours prior to sacrifice. Control mice received the same volume of phosphate-buffered saline on the same schedule. The animals were weighed and tumor volumes were measured twice weekly throughout the drug treatment period.

\section{Western blots}

Whole-cell extracts were prepared with a nuclear extraction TransAm Kit (Active Motif, Carlsbad, CA, USA) and Western blotting was carried out as previously described. ${ }^{21,22}$ Briefly, samples were subjected to Western blot analysis (30-40 $\mu \mathrm{g}$ ) in a NuPAGE 10\% Bis-Tris Gel (Thermo Fisher Scientific). Blots were blocked with 5\% nonfat dry milk in Tris-buffered saline, $0.1 \%$ Tween 20 for 1 hour at room temperature (RT), and then the blots were treated with a 1:200 dilution of primary antibody for 2 hours at RT. Blots were then incubated with secondary antibody $(1: 3,000$ dilution) for 1 hour at RT and washed seven times with Trisbuffered saline, $0.1 \%$ Tween 20 . Immunoreactive bands were visualized using an ECL Plus Detection Kit (Amersham, Pharmacia Biotech, Arlington Heights, IL, USA). Membranes were stripped and reprobed for $\beta$-actin, which was used as a protein loading control.

\section{Statistical analysis}

Differences between groups or among groups were tested by either paired $t$-test or by using one-way analysis of variance (ANOVA) with repeated measures over time. The assumption of the ANOVA was examined, and a nonparametric measure based on ranks was used if needed. When ANOVA indicated a significant effect (F-ratio, $P<0.05$ ), the StudentNewman-Keuls multirange test was used to compare the means of the individual groups. Statistical analyses were conducted using SigmaPlot software, version 12.5 (San Jose, CA, USA). For all comparisons, $P<0.05$ was regarded as statistically significant. Values are reported as mean \pm standard error of the mean.

\section{Results $\mathrm{RO}$ reduces prostate cancer cell viability in vitro}

We initially determined the dose-response and time-dependent effect of RO on prostate cancer cells in vitro using a cell viability assay. ${ }^{18}$ After 24 or 48 hours exposure to RO, the viability of both hormone-dependent (LNCaP) cells and castrationresistant (PC-3 and DU145) prostate cancer cells was reduced, with an half maximal inhibitory concentration $\left(\mathrm{IC}_{50}\right)$ value of $\sim 10 \mu \mathrm{M}$ (Figure 1A and Table 1). We also conducted studies using normal RWPE-1 prostate cells to determine whether RO specifically affects prostate cancer cells. When RWPE-1 cells were exposed to concentrations of RO of up to $10 \mu \mathrm{M}$, no effect was observed, whereas PC-3 prostate cancer cells exhibited significantly reduced viability (Figure 1B). This suggests that RO may be used against prostate cancer cells with little or no toxicity to normal prostate cells.

The affinity of RO for OSC is in the nM range. ${ }^{10,11}$ With this in mind, we performed studies over an extended period of time ( 7 days) to determine whether a range of low doses of RO would affect cell viability in a manner comparable with shorter term (24-48 hours) exposure to higher doses. Concentrations of $\mathrm{RO}$ as low as $1 \mathrm{nM}$ significantly reduced the viability of both LNCaP (hormone-dependent) and PC-3 (castration-resistant) cells in a 7-day assay (Figure 2).

\section{RO induces apoptosis in prostate cancer cells in vitro}

We next studied the mechanism of action through which RO reduces prostate cancer cell viability. The hormone-dependent prostate cancer cell lines $\mathrm{LNCaP}$ and its castration-resistant variant C4-2 were incubated with 10-30 $\mu \mathrm{M}$ RO for 24 hours, after which apoptosis was measured by Annexin V-FITC-based fluorescence-activated cell sorting analysis. $\mathrm{RO}$ induced apoptosis of both cell lines in a dose-dependent manner (Figure 3A). Interestingly, castration-resistant PC-3 and DU145 cells also demonstrated significant levels of apoptosis following 24-hour treatment with RO (Figure 3B).

\section{$R O$ reduces $A R$ protein expression and increases $E R \beta$ protein expression in prostate cancer cells in vitro}

Because AR is the main driving force for growth of both hormone-dependent and castration-resistant prostate cancer 

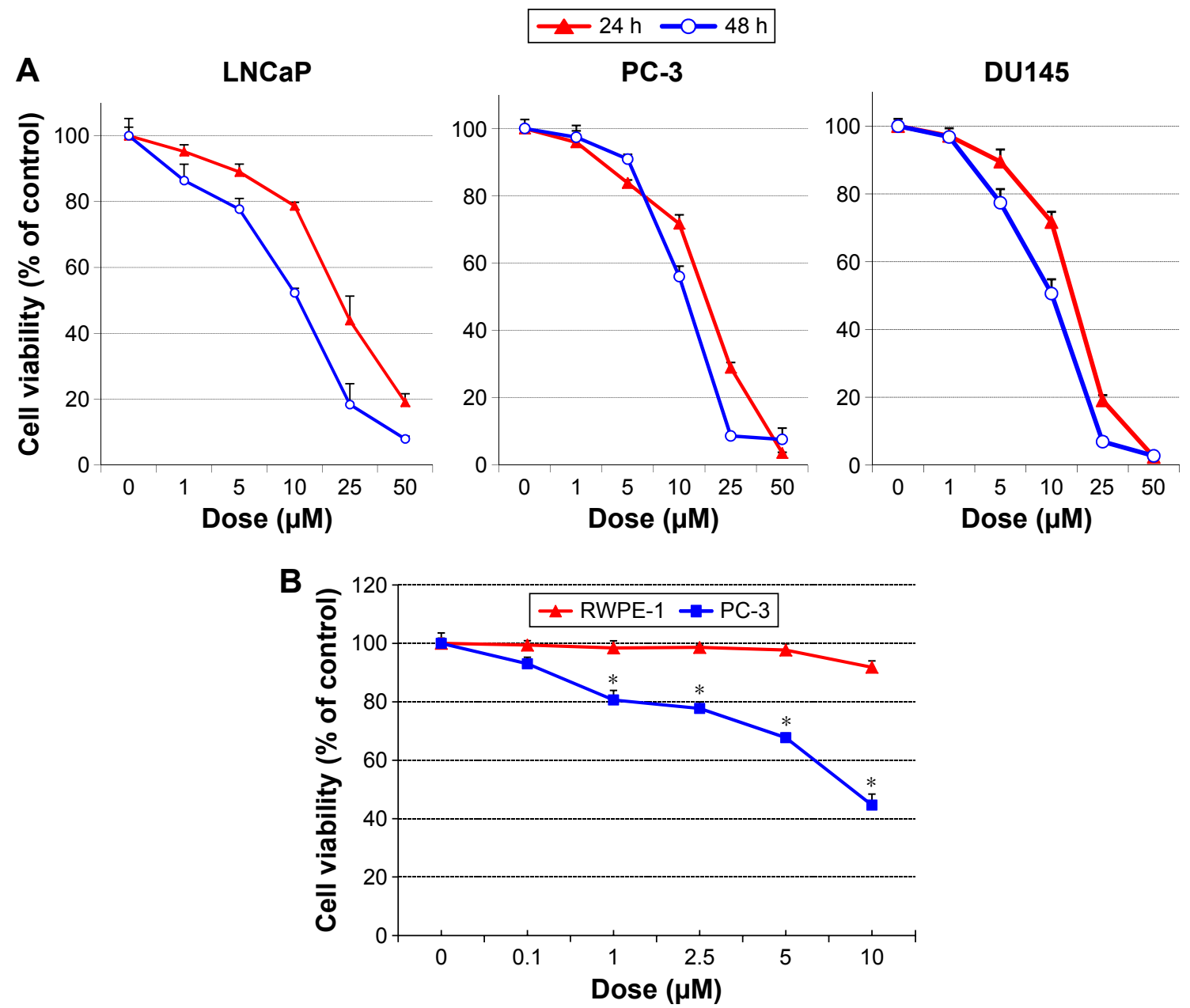

Figure I RO inhibits the viability of prostate cancer cells, but not normal prostate cells, in vitro.

Notes: (A) RO reduces viability of hormone-dependent (LNCaP) and castration-resistant (PC-3) prostate cancer cell lines. LNCaP cells (7×I03/well) in $20 \%$ FBS RPMI1640 medium and PC-3 cells ( $4 \times 10^{3} /$ well) and DUI 45 cells $\left(4 \times 10^{3} /\right.$ well) in 10\% FBS RPMI- 1640 medium were seeded in 96 -well plates overnight. Cells were then treated with different concentrations of RO in 5\% FBS RPMI-1640 medium (PC-3 and DUI45) or 10\% FBS RPMI-1640 medium (LNCaP) for 24 or 48 hours. Cell viability was evaluated

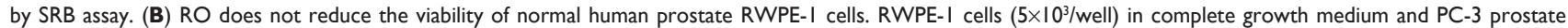
cancer cells $\left(4 \times 10^{3} /\right.$ well) in 10\% FBS RPMI- 1640 medium were seeded in 96 -well plates overnight. Cells were washed once with medium without FBS and then treated with different concentrations of RO in 5\% FBS RPMI- 1640 medium (PC-3 cells) or complete growth medium (RWPE-I cells) for 24 hours. Cell viability was evaluated by SRB assay. *Significantly different from controls $(P<0.05$, Paired $t$-test).

Abbreviations: FBS, fetal bovine serum; h, hours; RO, 4'-(6-[allylmethylamino]hexyloxy)-4-bromo-2'-fluorobenzophenone fumarate; RPMI-I640 medium, Roswell Park Memorial Institute 1640 medium; SRB, sulforhodamine B.

cells,${ }^{3-5}$ we performed studies in vitro to determine whether AR levels are affected by $\mathrm{RO}$ in these cells. In addition, we examined whether RO might also influence levels of ER $\beta$, which is a suppressor of tumor cell growth. ${ }^{15,16} \mathrm{LNCaP}$ prostate cancer cells (AR positive) were exposed to pharmacological

Table I Inhibition of prostate cancer cells with RO

\begin{tabular}{lll}
\hline Cell line & $\mathbf{2 4} \mathbf{h ~ I C}_{50}(\mu \mathrm{M})$ & $\mathbf{4 8} \mathbf{h ~ I C} \mathbf{~}_{50}(\mu \mathrm{M})$ \\
\hline LNCaP & $18.1 \pm 3.2$ & $11.8 \pm 0.4$ \\
PC-3 & $17.8 \pm I .3$ & $11 . I \pm 0.5$ \\
DUI45 & $13.5 \pm 0.9$ & $8.6 \pm 0.5$ \\
\hline
\end{tabular}

Note: Data shown as mean \pm SEM.

Abbreviations: $\mathrm{IC}_{50}$, half maximal inhibitory concentration; RO, 4'-(6-[allylmethylamino] hexyloxy)-4-bromo-2'-fluorobenzophenone fumarate; SEM, standard error of the mean.
(10-25 $\mu \mathrm{M})$ doses of RO in a short-term (6 hours) study; long-term studies were also performed using low $(0.1-1 \mu \mathrm{M})$ RO doses for 7 days. In both short- and long-term studies, treatment with RO reduced AR protein expression in a dose-dependent manner (Figure 4A and B). Importantly, RO increased ER $\beta$ protein expression dose-dependently in both hormone-dependent LNCaP and castration-resistant PC-3 cells in short-term studies (Figure 4C). Our findings therefore indicate that treatment of prostate cancer cells with $\mathrm{RO}$ reduces levels of pro-proliferative AR while simultaneously increasing antiproliferative ER $\beta$. We have previously reported such off-target effects of RO on ER $\alpha$ and ER $\beta$ in breast cancer cells in vitro. ${ }^{23,24}$ 

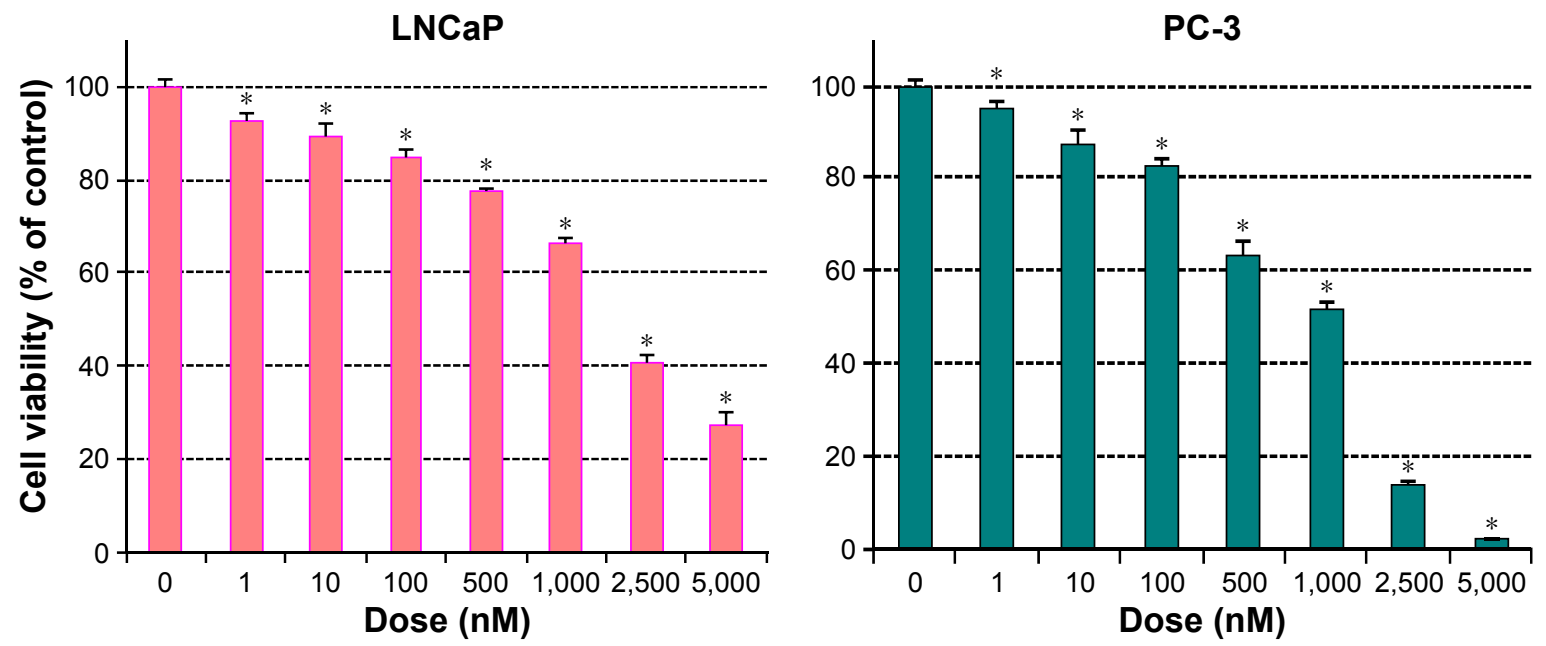

Figure 2 Low-dose (nM) treatment for 7 days with RO reduces viability of prostate cancer cells in vitro.

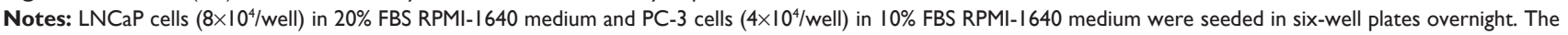
cells were washed with medium without FBS and then treated with different concentrations of RO in 5\% FBS RPMI-I640 medium (PC-3) or I0\% FBS RPMI-I640 medium $(\mathrm{LNCaP})$ for 7 days. Cells were retreated with the same concentration of RO every 48 hours. Cell viability was evaluated by SRB assay. ${ }^{*}$ Significantly different from controls $(P<0.05$, ANOVA).

Abbreviations: ANOVA, analysis of variance; FBS, fetal bovine serum; RO, 4'(6-[allylmethylamino]hexyloxy)-4-bromo-2'-fluorobenzophenone fumarate; RPMI-I640 medium, Roswell Park Memorial Institute 1640 medium; SRB, sulforhodamine B.
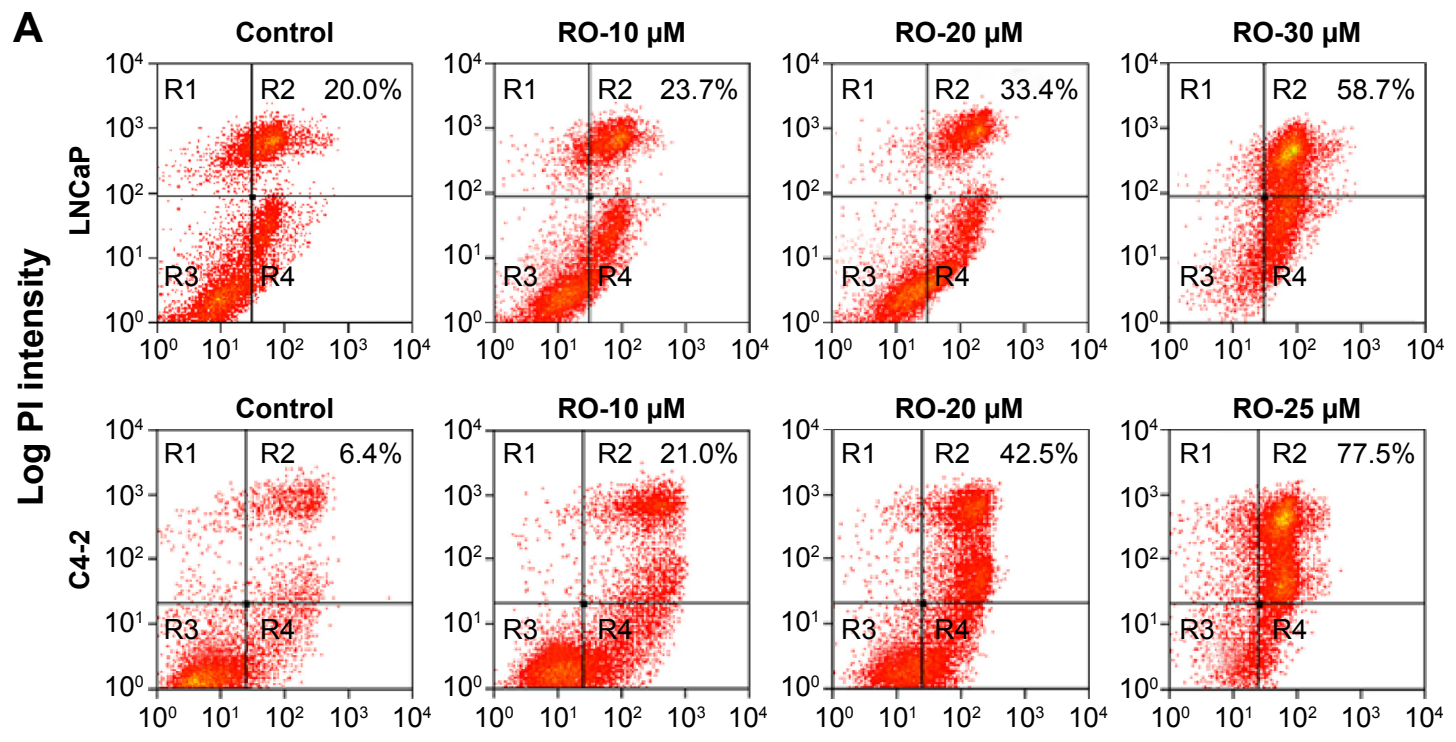

Log Annexin V-FITC intensity

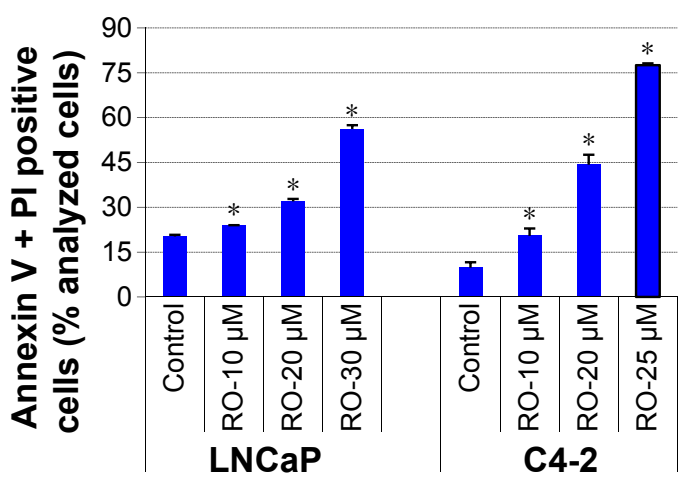

Figure 3 (Continued) 
B

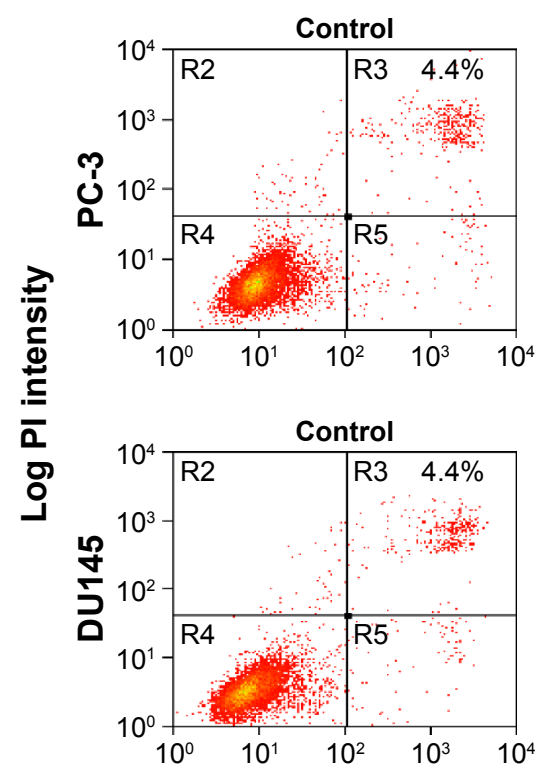

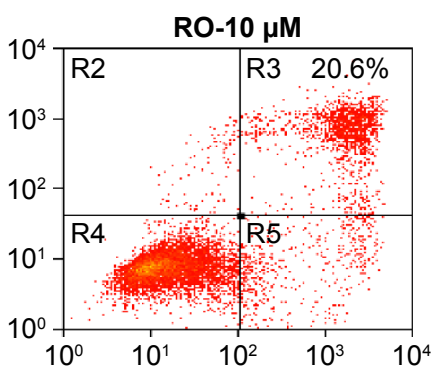
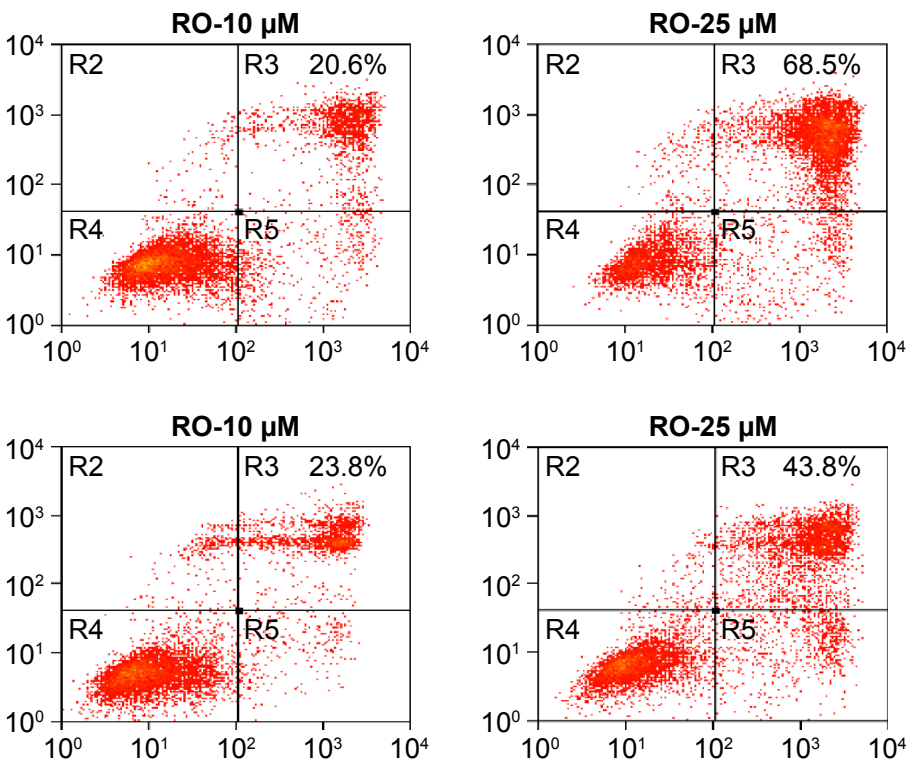

Log Annexin V-FITC intensity

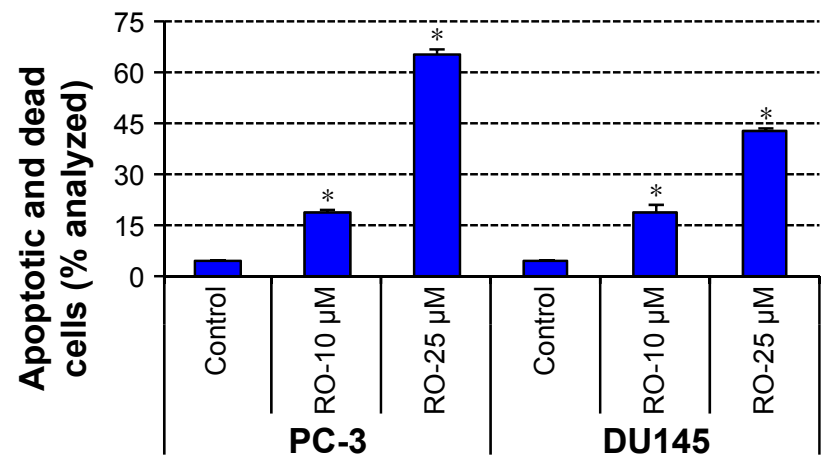

Figure 3 RO induces apoptosis in prostate cancer cells in vitro.

Notes: (A) RO induces apoptosis in hormone-dependent LNCaP and LNCaP-derived castration-resistant C4-2 prostate cancer cells. LNCaP cells (4×I05/well) in 20\% FBS RPMI- 1640 medium and C4-2 cells (3×105/well) in 10\% FBS RPMI-1640 medium were seeded in six-well plates overnight. The cells were washed once with RPMI-1640 medium without FBS and then treated with indicated $(\mu \mathrm{M})$ concentrations of RO in 10\% FBS RPMI-I640 medium (LNCaP) or 5\% FBS RPMI-I640 medium (C4-2) for 24 hours. Quantitation of apoptotic and dead cells was determined by Annexin V-FITC-based FACS analysis. *Significantly different from controls ( $P<0.05$, ANOVA). (B) RO induces apoptosis in castration-resistant PC-3 and DUI 45 prostate cancer cells. PC-3 and DUI 45 cells were seeded (3×I05/well) in I0\% FBS RPMI-I640 medium in six-well plates overnight. Treatment with RO and quantitation of apoptotic and dead cells were determined by Annexin V-FITC-based FACS analysis as described in (A). *Significantly different from controls $(P<0.05$, ANOVA).

Abbreviations: ANOVA, analysis of variance; FACS, fluorescence-activated cell sorting; FBS, fetal bovine serum; FITC, fluorescein isothiocyanate; PI, propidium iodide; RO, 4'-(6-[allylmethylamino]hexyloxy)-4-bromo-2'-fluorobenzophenone fumarate; RPMI-I640 medium, Roswell Park Memorial Institute I640 medium.

\section{Stimulation of ER $\beta$ activity enhances the ability of RO to reduce prostate cancer} cell viability in vitro

ER $\beta$ plays an antiproliferative role in prostate cancer cells. ${ }^{25-27}$ In order to determine whether induction of ER $\beta$ protein potentiates the antiproliferative effects of $\mathrm{RO}$, we treated castration-resistant PC-3 prostate cancer cells with $\mathrm{RO}$ in the presence of DPN, an ER $\beta$ agonist. Exposure of PC-3 cells to both DPN and RO reduced cell viability synergistically (Figure 5), suggesting that activation of ER $\beta$ is partially responsible for RO-mediated effects on prostate cancer cell viability.

\section{RO suppresses growth of prostate cancer cell xenografts in vivo}

Having demonstrated the effectiveness of RO in suppressing prostate cancer cell growth in vitro, we conducted studies to establish whether RO had the same effect in vivo. Castrationresistant PC-3 prostate cancer cells were used to establish xenografts in 6-week-old mice. Subsequent treatment with either 5 or $20 \mathrm{mg} / \mathrm{kg}$ RO significantly reduced in vivo tumor growth compared with vehicle-treated controls (Figure 6A). Furthermore, animal weights were unaffected by RO treatment compared with vehicle-treated controls (Figure 6B), indicating that the compound was nontoxic at the doses 
A

LNCaP

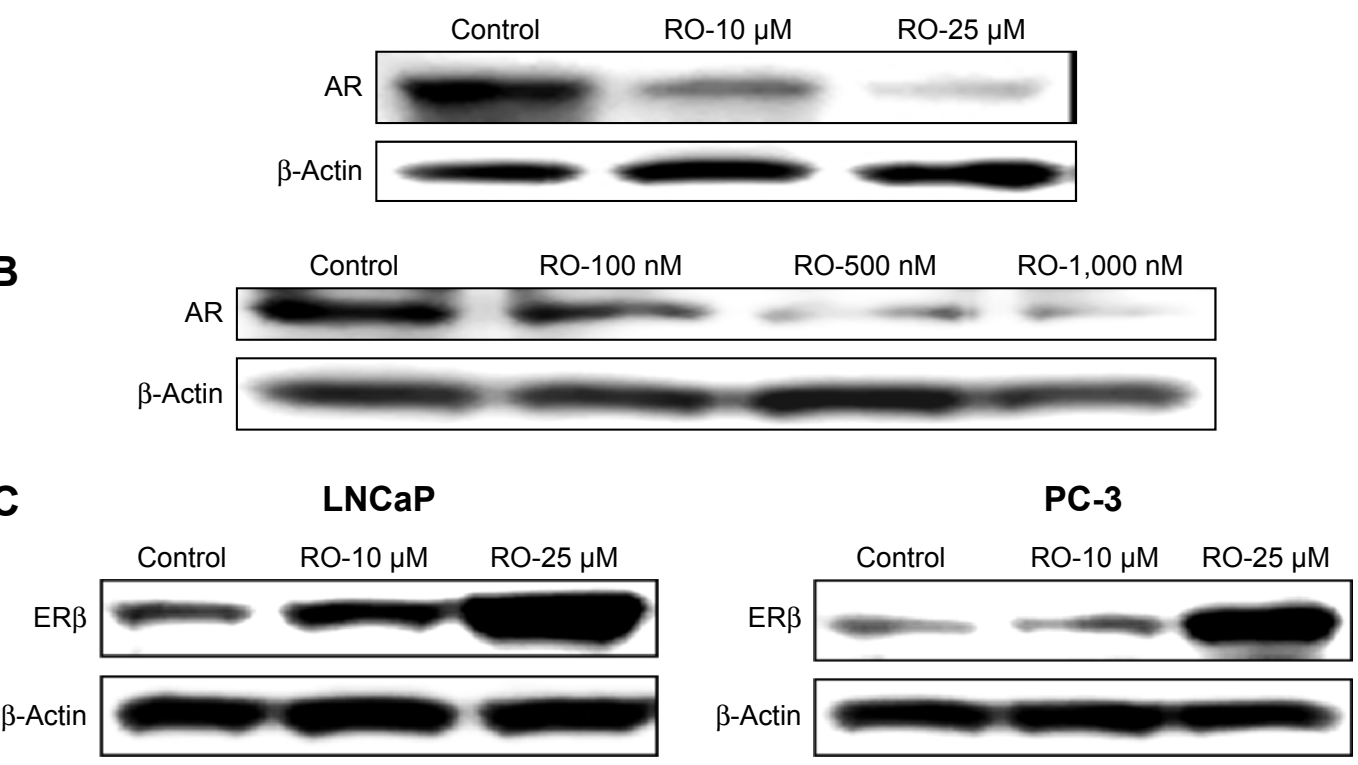

Figure 4 RO reduces $A R$ protein expression and increases $E R \beta$ protein expression in prostate cancer cells in vitro.

Notes: (A, B) RO reduces AR protein expression in LNCaP prostate cancer cells. (A) LNCaP cells were grown in $20 \%$ FBS RPMI-I640 medium. At $70 \%$ confluency, the cells were treated with $10 \mu \mathrm{M}$ or $25 \mu \mathrm{M}$ RO for 6 hours, after which whole-cell extracts were prepared and subjected to Western blot analysis with anti-AR antibodies. (B) LNCaP cells were grown in 20\% FBS RPMI- 1640 medium. At $70 \%$ confluency, the cells were treated with different concentrations of RO (0.I-I.0 $\mu$ M) for 7 days, after which whole-cell extracts were prepared and subjected to Western blot analysis with anti-AR antibodies. (C) RO induces ER $\beta$ expression in hormone-dependent LNCaP and castration-resistant PC-3 prostate cancer cells. LNCaP cells and PC-3 cells were grown in 20\% and I0\% FBS RPMI-I640 medium, respectively. At $70 \%$ confluency, the cells were treated with $10 \mu \mathrm{M}$ or $25 \mu \mathrm{M}$ RO for 6 hours, after which whole-cell extracts were prepared and subjected to Western blot analysis with anti-ER $\beta$ antibodies. $\beta$-Actin was used as a loading control.

Abbreviations: AR, androgen receptor; ER $\beta$, estrogen receptor $\beta$; FBS, fetal bovine serum; RO, 4'-(6-[allylmethylamino]hexyloxy)-4-bromo-2'-fluorobenzophenone fumarate; RPMI- 1640 medium, Roswell Park Memorial Institute 1640 medium.

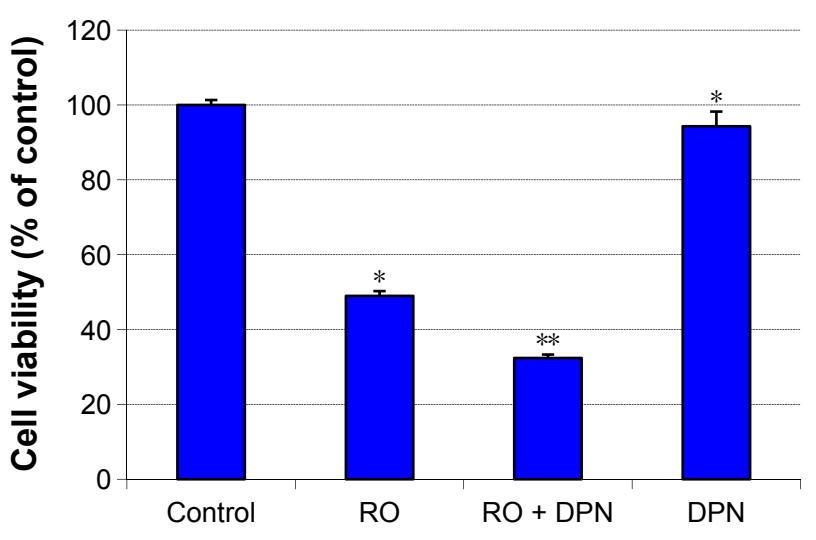

Figure 5 Stimulation of $E R \beta$ activity potentiates the ability of $R O$ to reduce viability of prostate cancer cells in vitro.

Notes: PC-3 cells $\left(4 \times 10^{3} /\right.$ well) in 10\% FBS RPMI- 1640 medium were seeded in 96-well plates overnight and washed once with RPMI-1640 medium without FBS. Cells from RO alone and RO + DPN groups were pretreated with $15 \mu \mathrm{M}$ RO for 2 hours and then treated with $15 \mu \mathrm{M}$ RO alone or $15 \mu \mathrm{M} R O+100 \mathrm{nM}$ DPN for 22 hours. Cells of the DPN group were treated with $100 \mathrm{nM}$ DPN alone for 22 hours without pretreatment (dose of DPN taken from previous studies ${ }^{13,20}$ ). Cell viability was evaluated by SRB assay. *Significantly different from controls, **significantly different from RO and DPN alone ( $P<0.00$ I, ANOVA). DPN alone was also significantly different from control at $P=0.041$ (ANOVA), representing inhibition of cell viability with low levels of ligand-bound endogenous ER $\beta$ (no RO treatment).

Abbreviations: ANOVA, analysis of variance; DPN, diarylpropionitrile; ER $\beta$ estrogen receptor $\beta$; FBS, fetal bovine serum; RO, 4'-(6-[allylmethylamino] hexyloxy)-4-bromo-2'-fluorobenzophenone fumarate; RPMI-I640 medium, Roswell Park Memorial Institute 1640 medium; SRB, sulforhodamine B. administered. In addition, two of the 12 tumors being monitored in the mice administered with $20 \mathrm{mg} / \mathrm{kg}$ RO were completely eradicated in the timeframe tested (Figure 6C).

\section{Discussion}

The risk of prostate cancer increases with a males age, though other risk factors, such as race and family history, may predispose certain individuals to developing the disease earlier. ${ }^{1-3}$ Prostate cancer is a deadly disease that, in its early stages, expresses functional AR and is consequently hormone dependent. At this point, patients respond to anti-androgen treatment. However, although a number of antihormonal treatment strategies are currently employed to control progression of the disease, drug-resistant tumors frequently emerge. ${ }^{4,5}$ Cancers that become nonresponsive to antihormone therapy are termed castration-resistant, even though AR still plays a role in these tumors. ${ }^{28}$ Patients with antihormone-resistant tumors have a poor prognosis, ${ }^{29,30}$ and, because treating such tumors is so challenging, new ways to control this type of disease are urgently sought.

In recent reports, we have shown that $\mathrm{RO}$, an inhibitor of OSC that prevents cholesterol biosynthesis, arrests the 

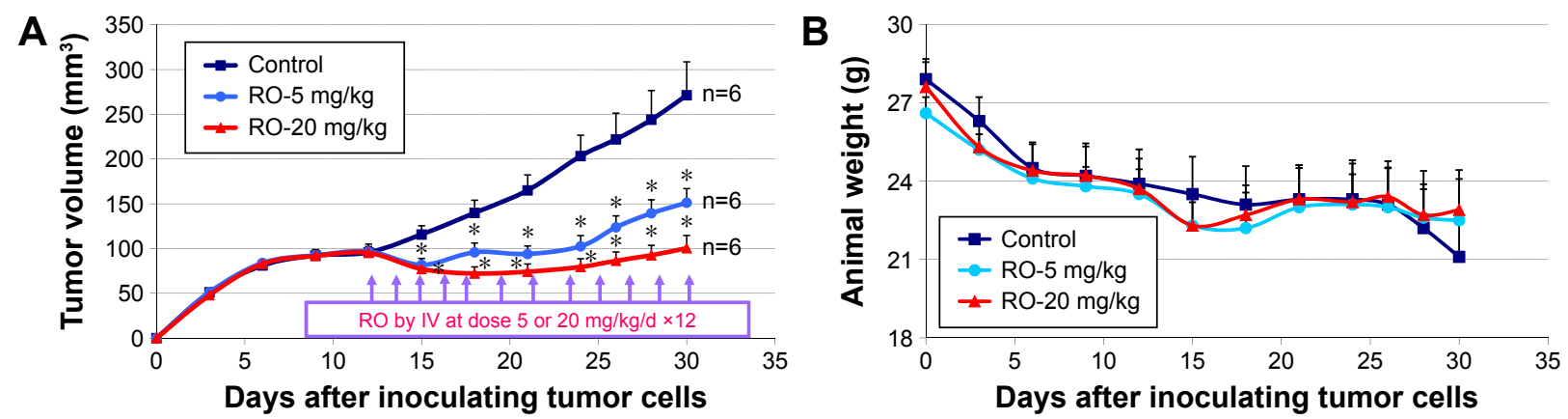

C

PC-3 tumors
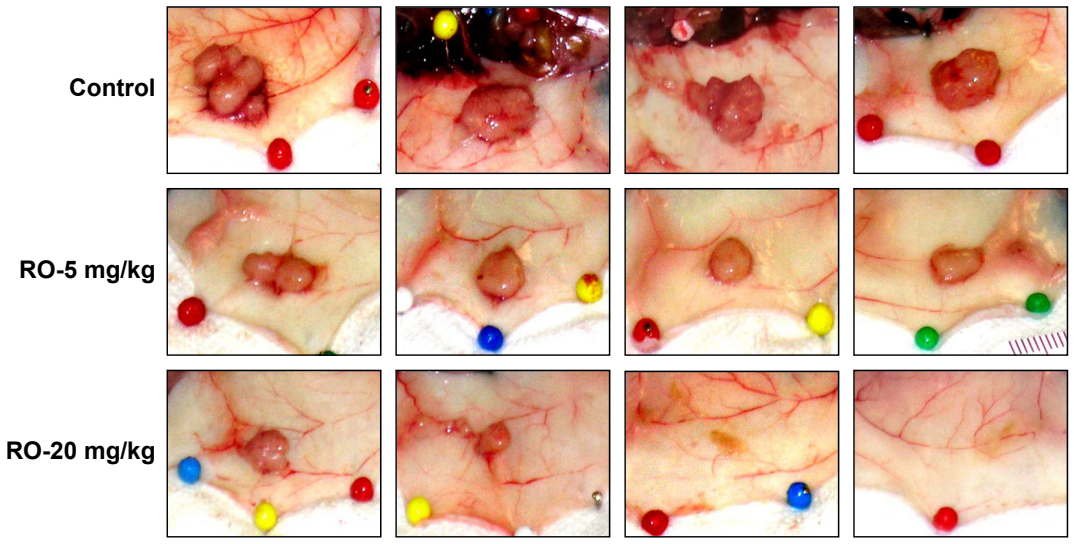

Figure 6 RO suppresses the growth of prostate cancer cell xenografts in vivo but does not affect animal weight.

Notes: (A) RO suppresses the growth of PC-3 prostate cancer cell xenografts in vivo. PC-3 cells $\left(5 \times 10^{6}\right.$ in $0.15 \mathrm{~mL}$ solution) were mixed with matrigel and RPMI1640 medium (I/I, v/v) and injected subcutaneously into both flanks of 6-week-old male athymic nu/nu nude mice. Tumors were allowed to develop and tumor volume monitored. When tumor volume reached $\sim 100 \mathrm{~mm}^{3}$, the animals were randomly assigned to three groups ( $\left.\mathrm{n}=6 / \mathrm{group}\right)$. RO was administered by tail vein injection, beginning with 5 or $20 \mathrm{mg} / \mathrm{kg} / \mathrm{d}$ for 5 days (loading dose), followed by the same dosing every other day for six additional treatments, followed by a final injection 2 hours before sacrifice, as indicated by the arrows in the figure. Animals in the control group received the vehicle alone under identical conditions. *Significantly different from control group ( $P<0.05$, ANOVA). (B) RO is nontoxic to tumor-bearing nude mice. Animal weights were monitored throughout the experiment, as shown in $\mathbf{A}$. No significant differences in animal weights were observed between control animals and those treated with RO. (C) Representative tumor images from the experiment are described in A. Tumors were photographed at the end of the experiment. Two out of 12 tumors in the $20 \mathrm{mg} / \mathrm{kg}$ RO group were completely eradicated, as shown in the two right hand images in the bottom row.

Abbreviations: ANOVA, analysis of variance; RO, 4'-(6-[allylmethylamino]hexyloxy)-4-bromo-2'-fluorobenzophenone fumarate; RPMI-I640 medium, Roswell Park Memorial Institute 1640 medium.

growth of breast cancer cells. ${ }^{23,24}$ We further showed in vitro that $\mathrm{RO}$ also abolished AR-dependent transcriptional activity ${ }^{31}$ leading us to conduct the present studies investigating the ability of $\mathrm{RO}$ to suppress the growth of prostate cancer cells. In the studies reported here, RO reduced the viability of three prostate cancer cell lines: hormonedependent LNCaP cells, as well as castration-resistant PC-3 and DU145 cells. While the growth of LNCaP cells is AR-dependent and responsive to androgens; the other cell lines are resistant to antihormone therapy. We also determined that concentrations of RO up to $10 \mu \mathrm{M}$ had no effect on the viability of normal prostate cells, suggesting that its in vitro effects are specific to cancerous prostate cells. We therefore propose that because $\mathrm{RO}$ appears to be nontoxic to normal cells, it might be used to target tumors with little risk of patient toxicity. Our subsequent in vivo studies discussed later support this notion, further indicating that the use of
$\mathrm{RO}$ as a therapeutic agent is a possibility with little or no risk of toxic side effects.

In order to better understand how RO exerts its antitumor properties, we first determined whether RO induces apoptosis in prostate cancer cells. Indeed, RO did induce apoptosis in a dose-dependent manner in both hormone-dependent and castration-resistant cells. It therefore appears that induction of apoptosis is likely the major mechanism of action of RO in vitro, a finding in accord with $\mathrm{RO}$ effects that we have previously reported in breast cancer cells. ${ }^{23,24}$

To further explore the mechanism of action of RO responsible for its effects in prostate cancer cells in vitro, we examined its influence on AR and ER $\beta$ protein expression. We observed a dramatic, dose-dependent reduction in AR protein expression in response to RO. Future studies will determine whether $\mathrm{RO}$ reduces AR transcription or reduces AR protein expression independent of effects on mRNA, 
directly affecting AR at the protein level. Additional studies will also include competition assays to ascertain whether or not RO binds directly to AR, given that there are strict structural requirements that facilitate the binding of AR to a ligand, and our previous data does not show transcriptional inhibition effect of RO on AR..$^{31,32}$

We also observed that RO induced ER $\beta$, which has been associated with reduced viability of prostate cancer cells, ${ }^{13-16}$ in both hormone-dependent LNCaP cells and castrationresistant PC-3 cells. This is particularly important as ER $\beta$ may potentially be targeted by specific drugs to potentiate its anticancer effects. Furthermore, the ER $\beta$-specific agonist DPN potentiated the effects of RO, further confirming the important role played by ER $\beta$ in reducing cell viability. We propose therefore that drugs such as DPN, which increase ER $\beta$ activity in prostate cancer cells, could be made even more effective when administered in conjunction with RO. The development of therapeutic regimens using a combination of two drugs might make it possible to manage disease using lower levels of both agents, reducing the likelihood of toxic side effects that arise from current therapeutic modalities. ${ }^{33}$ In future studies, we will examine in more detail the mechanism by which RO affects cellular ER $\beta$ levels by analyzing both RNA transcription and protein stability. We will also compare the growth inhibitory effects of RO with other cholesterol-lowering agents, such as statins.

Because castration-resistant prostate cancers are notoriously difficult to treat using current therapeutic protocols and respond poorly to clinical intervention, in this study, we selected castration-resistant PC-3 cells to examine the ability of RO to suppress prostate cancer cell xenografts in vivo. Compared with controls that did not receive $\mathrm{RO}$, growth of tumors in animals receiving RO was significantly suppressed, and two out of 12 tumors were completely eradicated in mice receiving the higher dose of $\mathrm{RO}$ in the timeframe tested. No RO-mediated toxicity was observed in mice, as we have previously reported. ${ }^{23}$ These findings suggest that RO could be an effective means by which to suppress the in vivo growth of cells that are resistant to antihormones. We plan to test this possibility in several other cell lines, as well as in patient-derived xenografts.

\section{Conclusion}

In summary, the data presented here strongly suggest that, in addition to its ability to suppress cholesterol biosynthesis, the OSC inhibitor RO has powerful antitumor properties. As well as inducing apoptosis of prostate cancer cells, RO also reduces levels of pro-proliferative protein AR and increases antiproliferative protein ER $\beta$ in these cells. Together, these activities may lead to a cellular milieu that favors reduced proliferation of prostate cancer cells, as has previously been shown with other agents. ${ }^{34,35}$ Certainly, when RO was given in combination with an ER $\beta$ agonist, inhibition of prostate cancer cell viability was even further enhanced, strongly suggesting that ER $\beta$ plays a central role in RO-mediated tumor cell growth suppression. We therefore propose that combination therapy using inhibitors of cholesterol biosynthesis such as RO, together with commonly used chemotherapeutic drugs or agents that specifically target and activate ER $\beta$ protein, could prove beneficial as a means of preventing the growth of prostate cancer tumors.

\section{Acknowledgments}

The studies reported were supported by the Department of Defense Prostate Cancer Program grant W81XWH-14-1-0246, by a peer-reviewed Committee on Research grant from the College of Veterinary Medicine, University of MissouriColumbia, and by generous support from donors of Ellis Fischel Cancer Center, University of Missouri-Columbia. We would also like to thank Dr Carolyn Henry for her invaluable support during the completion of this project. $\mathrm{SMH}$ is the Zalk Missouri Professor of Tumor Angiogenesis.

\section{Disclosure}

The authors report no conflicts of interest in this work.

\section{References}

1. Siegel RL, Miller KD, Jemal A. Cancer statistics, 2015. CA Cancer JClin. 2015;65(1):5-29.

2. Penson DF, Litwin MS. The physical burden of prostate cancer. Urol Clin North Am. 2003;30:305-313.

3. O'Shaughnessy JA, Kelloff GJ, Gordon GB, et al. Treatment and prevention of intraepithelial neoplasia: an important target for accelerated new agent development. Clin Cancer Res. 2002;8: 314-346.

4. Pelton K, Freeman MR, Solomon KR. Cholesterol and prostate cancer Curr Opin Pharmacol. 2012;12:751-759.

5. Ali S, Ali S. Multidimensional approaches in dealing with prostate cancer. Gene. 2008;410:1-8.

6. Solomon KR, Pelton K, Boucher K, et al. Ezetimibe is an inhibitor of tumor angiogenesis. Am J Pathol. 2009;174:1017-1026.

7. Garcia-Ruiz C, Morales A, Fernandez-Checa JC. Statins and protein prenylation in cancer cell biology and therapy. Anticancer Agents Med Chem. 2012;12:303-315.

8. McTaggart SJ. Isoprenylated proteins. Cell Mol Life Sci. 2006;63: $255-267$.

9. Charlton-Menys V, Durrington PN. Squalene synthase inhibitors: clinical pharmacology and cholesterol-lowering potential. Drugs. 2007; 67:11-16.

10. Morand OH, Aebi JD, Dehmlow H, et al. RO 48-8.071, a new 2,3oxidosqualene: lanosterol cyclase inhibitor lowering plasma cholesterol in hamsters, squirrel monkeys, and minipigs: comparison to simvastatin. J Lipid Res. 1997;38:373-390. 
11. Abe I, Zheng YF, Prestwich GD. Photoaffinity labeling of oxidosqualene cyclase and squalene cyclase by a benzophenone-containing inhibitor. Biochemistry. 1998;37:5779-5784.

12. Dondi D, Piccolella M, Biserni A, et al. Estrogen receptor beta and the progression of prostate cancer: role of 5alpha-androstane-3beta, 17betadiol. Endocr Relat Cancer. 2010;17:731-742.

13. Pravettoni A, Mornati O, Martini PG, et al. Estrogen receptor beta (ERbeta) and inhibition of prostate cancer cell proliferation: studies on the possible mechanism of action in DU145 cells. Mol Cell Endocrinol. 2007; 263:46-54.

14. Singh V, Sharma V, Verma V, et al. Apigenin manipulates the ubiquitinproteasome system to rescue estrogen receptor- $\beta$ from degradation and induce apoptosis in prostate cancer cells. Eur J Nutr. 2015;54: 1255-1267.

15. Dey P, Barros RP, Warner M, Ström A, Gustafsson JA. Insight into the mechanisms of action of estrogen receptor $\beta$ in the breast, prostate, colon, and CNS. J Mol Endocrinol. 2013;51:T61-T74.

16. Dey $\mathrm{P}$, Ström A, Gustafsson JA. Estrogen receptor $\beta$ upregulates FOXO3a and causes induction of apoptosis through PUMA in prostate cancer. Oncogene. 2014;33:4213-4225.

17. Harrington WR, Sheng S, Barnett DH, Petz LN, Katzenellenbogen JA, Katzenellenbogen BS. Activities of estrogen receptor alpha- and betaselective ligands at diverse estrogen responsive gene sites mediating transactivation or transrepression. Mol Cell Endocrinol. 2003;206: 13-22.

18. Rubinstein LV, Shoemaker RH, Paull KD, et al. Comparison of in vitro anticancer-drug-screening data generated with a tetrazolium assay versus a protein assay against a diverse panel of human tumor cell lines. J Natl Cancer Inst. 1990;82:1113-1118.

19. Liang Y, Brekken RA, Hyder SM. VEGF induces proliferation of breast cancer cells and counteracts the anti-proliferative activity of anti-hormones. Endocr Relat Cancer. 2006;13:905-919.

20. Liang Y, Besch-Williford C, Brekken RA, Hyder SM. Progestindependent progression of human breast tumor xenografts: a novel model for evaluating anti-tumor therapeutics. Cancer Res. 2007;67: 9929-9936.

21. Liang Y, Besch-Williford C, Benakanakere I, Hyder SM. Re-activation of p53 pathway inhibits growth of hormone-dependent human breast cancer cells in vitro and in vivo. Int J Oncol. 2007;31:777-784.

22. Liang Y, Besch-Williford C, Benakanakere I, Thorpe PE, Hyder SM. Targeting mutant p53 protein and the tumor vasculature: an effective combination therapy for advanced breast tumors. Breast Cancer Res Treat. 2011;125:407-420.

23. Liang Y, Besch-Williford C, Aebi JD, et al. Cholesterol biosynthesis inhibitors as potent novel anti-cancer agents: suppression of hormonedependent breast cancer by the oxidosqualene cyclase inhibitor RO 48-8071. Breast Cancer Res Treat. 2014;146:51-62.
24. Grinter SZ, Liang Y, Huang SY, Hyder SM, Zou X. An inverse docking approach for identifying new potential anti-cancer targets. J Mol Graph Model. 2011;29:795-799.

25. Cheng J, Lee EJ, Madison LD, Lazennec G. Expression of estrogen receptor beta in prostate carcinoma cells inhibits invasion and proliferation and triggers apoptosis. FEBS Lett. 2004;566:169-172.

26. Sharma V, Verma V, Lal N, et al. Disulfiram and its novel derivative sensitize prostate cancer cells to the growth regulatory mechanisms of the cell by re-expressing the epigenetically repressed tumor suppressorestrogen receptor $\beta$. Mol Carcinog. Epub 2015 Nov 24.

27. Hussain S, Lawrence MG, Taylor RA, et al. Estrogen receptor $\beta$ activation impairs prostatic regeneration by inducing apoptosis in murine and human stem/progenitor enriched cell populations. PLoS One. 2012;7:e40732.

28. Shen HC, Shanmugasundaram K, Simon NI, et al. In silico discovery of androgen receptor antagonists with activity in castration resistant prostate cancer. Mol Endocrinol. 2012;26:1836-1846.

29. Di Lorenzo G, Bracarda S, Buonerba C, Aieta M, Mirone V. Poor survival in prostate cancer patients with primary refractoriness to docetaxel. Eur Urol. 2014;65:505-507.

30. Rajan P, Sudbery IM, Villasevil ME, et al. Next-generation sequencing of advanced prostate cancer treated with androgen-deprivation therapy. Eur Urol. 2014;66:32-39.

31. Mafuvadze B, Liang Y, Hyder SM. Cholesterol synthesis inhibitor RO 48-8071 suppresses transcriptional activity of human estrogen and androgen receptor. Oncol Rep. 2014;32:1727-1733.

32. Tan MH, Li J, Xu HE, Melcher K, Yong EL. Androgen receptor: structure, role in prostate cancer and drug discovery. Acta Pharmacol Sin. 2015;36:3-23.

33. Boegemann M, Schrader AJ, Krabbe LM, Herrmann E. Present, emerging and possible future biomarkers in castration resistant prostate cancer (CRPC). Curr Cancer Drug Targets. 2015;15:243-255.

34. Shazer RL, Jain A, Galkin AV, et al. Raloxifene, an oestrogen-receptorbeta-targeted therapy, inhibits androgen-independent prostate cancer growth: results from preclinical studies and a pilot phase II clinical trial. BJU Int. 2006;97:691-697.

35. Lai KP, Huang CK, Chang YJ, et al. New therapeutic approach to suppress castration-resistant prostate cancer using ASC-J9 via targeting androgen receptor in selective prostate cells. Am J Pathol. 2013;182: $460-473$.
OncoTargets and Therapy

\section{Publish your work in this journal}

OncoTargets and Therapy is an international, peer-reviewed, open access journal focusing on the pathological basis of all cancers, potential targets for therapy and treatment protocols employed to improve the management of cancer patients. The journal also focuses on the impact of management programs and new therapeutic agents and protocols on

\section{Dovepress}

patient perspectives such as quality of life, adherence and satisfaction The manuscript management system is completely online and includes a very quick and fair peer-review system, which is all easy to use. Visit http://www.dovepress.com/testimonials.php to read real quotes from published authors. 